This item was submitted to Loughborough's Research Repository by the author.

Items in Figshare are protected by copyright, with all rights reserved, unless otherwise indicated.

\title{
The effect of a post-activation annealing treatment on thin film CdTe device performance
}

PLEASE CITE THE PUBLISHED VERSION

http://dx.doi.org/10.1109/PVSC.2015.7356441

PUBLISHER

(C) IEEE

VERSION

AM (Accepted Manuscript)

LICENCE

CC BY-NC-ND 4.0

\section{REPOSITORY RECORD}

Abbas, Ali, Drew E. Swanson, Amit Munshi, Kurt L. Barth, Walajabad S. Sampath, G.D. West, Jake W. Bowers, Piotr M. Kaminski, and Michael Walls. 2019. "The Effect of a Post-activation Annealing Treatment on Thin Film Cdte Device Performance”. figshare. https://hdl.handle.net/2134/20608. 


\title{
The Effect of a Post-Activation Annealing Treatment on Thin Film CdTe Device Performance
}

\author{
A. Abbas' ${ }^{1}$ D. Swanson' ${ }^{2}$ A. Munshi ${ }^{2}$, K.L. Barth ${ }^{2}$, W.S. Sampath ${ }^{2}$ \\ G.D West ${ }^{1}$, J.W. Bowers ${ }^{1}$, P.M. Kaminski ${ }^{1}$ and J.M. Walls ${ }^{1}$, \\ ${ }^{1}$ Loughborough University, Loughborough, United Kingdom, ${ }^{2}$ NSF I/UCRC for Next Generation \\ Photovoltaics, Colorado State University, Fort Collins, United States
}

\begin{abstract}
The cadmium chloride activation treatment of cadmium telluride solar cells is essential for producing high efficiency devices. The treatment has many effects but the most significant is the complete removal of stacking faults in the cadmium telluride grains and the diffusion of Chlorine along the grain boundaries of the device. Chlorine decorates all cadmium telluride and cadmium sulphide grain boundaries and also builds up along the $\mathrm{CdTe} / \mathrm{CdS}$ junction. - This paper reveals that by annealing devices to temperatures of $400^{\circ} \mathrm{C}$ to $480{ }^{\circ} \mathrm{C}$ for times ranging from 30 to 600 seconds in moderate vacuum results in the reappearance of stacking faults and the removal of Choline from the grain boundaries. STEM analysis confirms the reappearance of the stacking faults and SIMS and EDX confirm the removal of chlorine from the grain boundaries. This directly corresponds to a lowering in cell efficiency. The study provides further evidence that $\mathbf{C d C l}_{2}$ diffusion and certain microstructural defects directly affect the performance of cadmium telluride photovoltaic devices.
\end{abstract}

Index Terms - CdTe, PV, $\mathrm{CdCl}_{2}$, TEM, EDX, SIMS

\section{INTRODUCTION}

Cadmium telluride is an important photovoltaic material used as an absorber due to its excellent properties for photon conversion currently exceeding an annual production of 2 GW. Laboratory cell efficiencies have reached $21.5 \%$ and commercial module efficiencies of $17 \%$ have been reported [1]. An essential step in the production of efficient thin film cadmium telluride solar cells is an activation process that involves treating the cadmium telluride layer with cadmium chloride at a temperature of $\sim 400^{\circ} \mathrm{C}[2,3]$. The as deposited material is polycrystalline and although the grain size depends on the method of deposition, all the methods produce material with high densities of planar defects such as stacking faults and twin boundaries [4]. Recent work using Density Functional Theory (DFT) has shown that certain types of stacking fault are high energy hole traps [5].

The cadmium chloride passivation causes the cadmium telluride grains to recrystallize. During recrystallization the planar stacking faults are completely eradicated. Twin boundaries often remain after the recrystallization, but work using DFT modeling shows these are electrically benign and do not act as hole traps[5]. Although over-treatment using higher temperatures or longer cadmium chloride treatment times continues to improve the morphology of the films, however chlorine builds up at the CdS/CdTe interface damaging the junction [5]. We have used a post-annealing process in an attempt to remove chlorine from the device. We have annealed cadmium telluride devices from $400^{\circ} \mathrm{C}$ to $480^{\circ} \mathrm{C}$, causing a reduction in efficiency. Microstructural and elemental characterization of these annealed devices has been carried out to determine the cause of the degradation of the cells. By using a second cadmium chloride treatment, identical to the first, which restored the cell efficiency. The microstructure and performance of these re-passivated devices has also been characterized.

\section{EXPERIMENTAL}

A. Cadmium Telluride Deposition and the Cadmium Chloride Activation Treatment

The thin film cadmium telluride cells were deposited in a superstrate configuration using closespaced sublimation (CSS) on NSG-Pilkington TEC10 fluorine doped tin oxide (FTO) coated on $3 \mathrm{~mm}$ soda lime glass. A thin layer of cadmium sulphide was deposited onto a plasma cleaned transparent conducting oxide [7]. This was followed by the CSS deposition of the cadmium telluride film. The devices then underwent a previously optimized post deposition cadmium chloride activation treatment [3]. This was followed by a copper doping process using copper chloride [3,8]. The efficiency of this cell was measured to be above $12 \%$. The cell efficiency before the cadmium chloride treatment was measured to be $<1 \%$.

\section{B. Post-Treatment Anneal}

The optimized devices were then post-annealed in a 40 mTorr Argon atmosphere. This post-annealing process was performed in the absence of a $\mathrm{CdCl}_{2}$ vapor pressure. The substrate temperatures used for the postannealing processes were $400^{\circ} \mathrm{C}, 440^{\circ} \mathrm{C}$ and $480^{\circ} \mathrm{C}$. The times used for the post-annealing process were also varied from 35 to 600 seconds. The sample treated at $480^{\circ} \mathrm{C}$ for 600 seconds underwent a second cadmium chloride treatment after the post-annealing treatment. 


\section{Characterization Methods}

Samples for Transmission Electron Microscopy (TEM) were prepared by Focused Ion Beam (FIB) milling using a dual beam FEI Nova 600 Nanolab. A standard in situ lift out method was used to prepare cross-sectional samples through the coating into the glass substrate. An electron beam assisted platinum (e-Pt) over-layer was deposited followed by an ion assisted layer to define the surface and homogenize the final thinning of the samples down to $100 \mathrm{~nm}$. TEM analysis was carried out using a Tecnai F20 operating at $200 \mathrm{kV}$ to investigate the detailed microstructures of the cell cross sections. The system was equipped with an Oxford instruments X-max N80 TLE SDD energy-dispersive X-ray spectroscopy (EDX) detector and this was used in STEM mode to collect elemental distribution maps. These maps were collected in a single frame using a long dwell time, as well as a small condenser aperture (70 microns) to minimize drift and beam spread during data collection. A Cameca IMS $3 F$ was used for secondary ion mass spectrometry (SIMS) depth profiling. The analysis was performed using $\mathrm{Cs}^{+}$ primary ion bombardment at $10 \mathrm{keV}$ with a current of 1 $\mu \mathrm{A}$ with a spot size of $60 \mu \mathrm{m}$ and negative secondary ion detection to optimise the sensitivity to chlorine.

\section{RESULTS}

\section{A. As-Deposited and Cadmium Chloride Treated Cells}

Figure 1a shows a high resolution image of an untreated cadmium telluride grain with a high density of planar defects. Lower resolution studies show that all the defects terminate at a grain boundary. Figure $1 \mathrm{~b}$ shows another high resolution image from a cadmium chloride treated cadmium telluride grain with a perfect lattice. This is typical for treated and untreated grains. After the cadmium chloride treatment large areas of the cadmium telluride grains appear defect free with the exception of the regular appearance of twin boundaries.

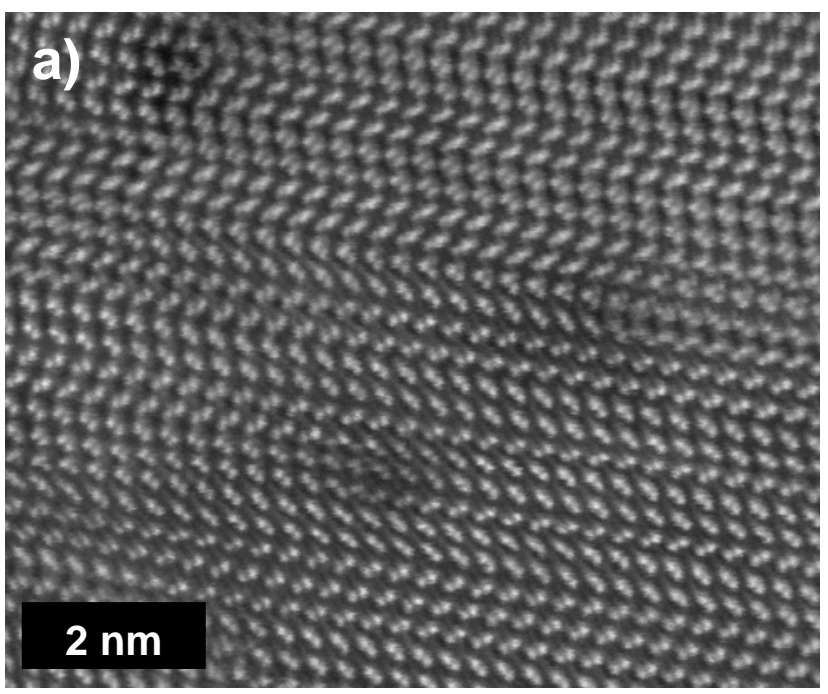

Fig. 1a. A STEM HRTEM lattice image from a cross-section of an untreated cadmium telluride layer, showing a high density of planar defects which are predominantly stacking faults.

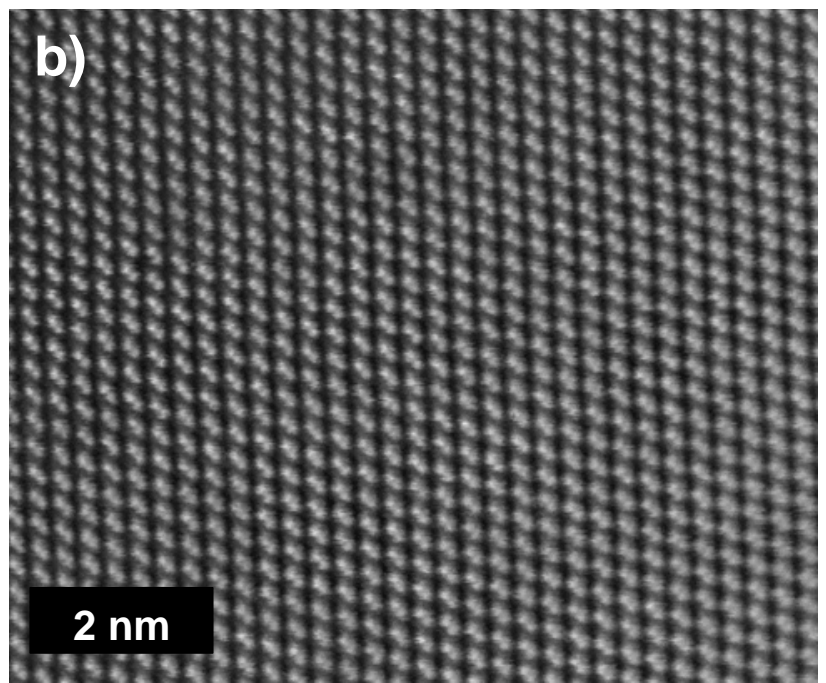

Fig. 1b. A STEM HRTEM image from a cross-section of a grain in a treated cadmium telluride layer. The density of planar defects has been dramatically reduced by the cadmium chloride treatment. This area shows a perfect lattice.

The removal of planar defects correlates with the diffusion of chlorine into the device. Figure 2 shows a dynamic SIMS depth profile using caesium ions, carried out on the cadmium chloride treated sample. The chlorine concentration in the cadmium telluride was quantified using reference standards. In the bulk cadmium telluride, the chlorine concentration is constant at 0.07 at $\%$ increasing slightly to 0.08 at\%. However, at the cadmium sulphide interface, the chlorine concentration peaks at 0.7 at\%. This concentration is an order of magnitude higher than that measured in the bulk cadmium telluride. The sulphur concentration-depth profile shows that the sulphur diffuses from the cadmium sulphide into the cadmium telluride layer.

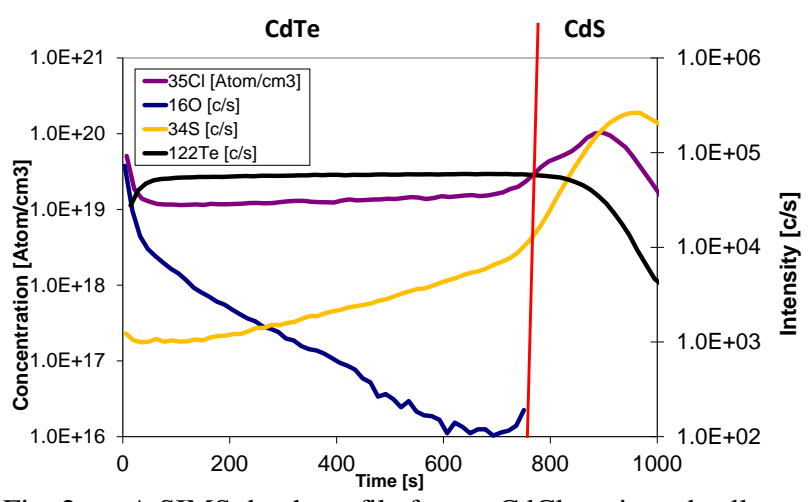

Fig. 2. A SIMS depth profile from a $\mathrm{CdCl}_{2}$ activated cell showing the distribution of $\mathrm{Cl}, \mathrm{S}, \mathrm{O}$ and Te through the device following diffusion during the activation process.

The STEM/EDX elemental maps shown in figure 3 are from a cadmium chloride passivated device. The cross-sectional image shows clear chlorine segregation along the cadmium telluride and cadmium sulphide grain boundaries as well as sulphur diffusion into the cadmium telluride film; however the chlorine does not penetrate into the FTO layer. Twin boundaries are clearly visible in the cadmium telluride grains but there is no trace of stacking faults. 


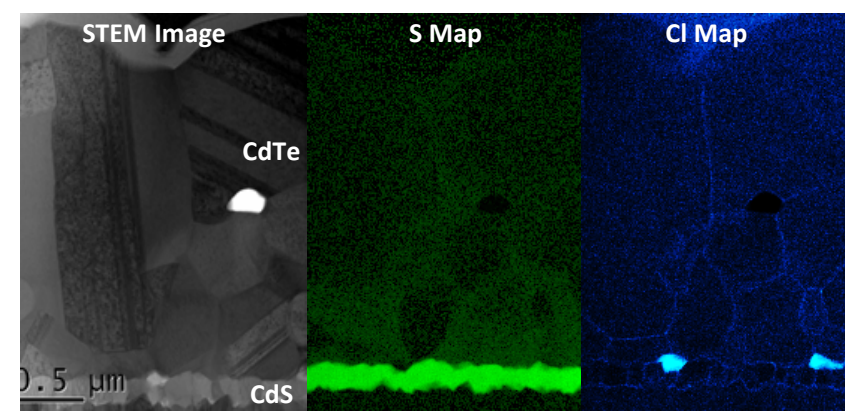

Fig. 3. A BF-STEM micrograph from a treated cell with corresponding EDX elemental maps for sulphur and chlorine. Chlorine decorates the CdTe and CdS grain boundaries and chlorine rich agglomerates are present at the junction.

\section{B. The Effect of the Post-Annealing Temperature on Passivated Cells}

Passivated cadmium telluride devices were postannealed at 3 different temperatures, $400^{\circ} \mathrm{C}, 440^{\circ} \mathrm{C}$ and $480^{\circ} \mathrm{C}$ for 35 seconds. The post-annealing treatment of the cadmium telluride devices caused a surprising reduction in efficiency. The treated devices had an average efficiency of $12 \%$ after the cadmium chloride treatment. Annealing at $400^{\circ} \mathrm{C}$ for 35 seconds caused a reduction in cell efficiency as shown in figure 4. Increasing the temperature to $480^{\circ} \mathrm{C}$ for 35 seconds caused a dramatic decrease in efficiency to $3 \%$.

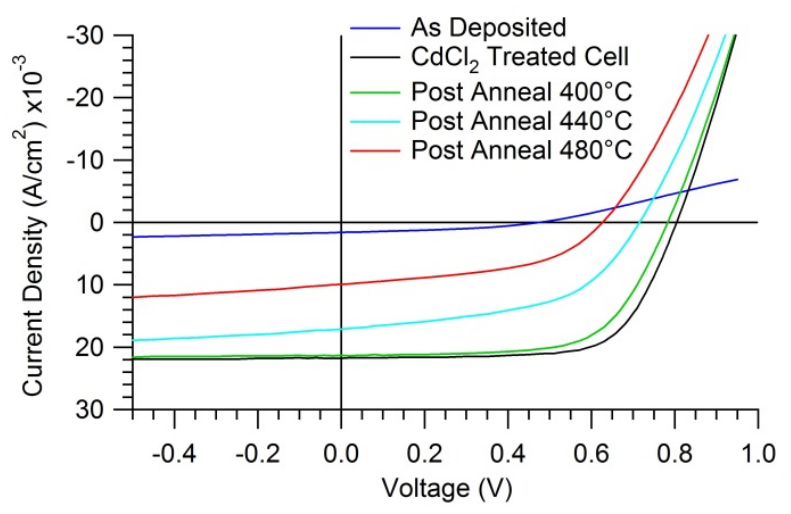

Fig. 4. J-V curves from an untreated and treated device together with the performance of activated cells following postannealing at $400{ }^{\circ} \mathrm{C}, 440{ }^{\circ} \mathrm{C}$ and $480^{\circ} \mathrm{C}$ for 35 seconds. The cell efficiency decreases sharply with increasing postannealing temperature.

Cross-sections of the post-annealed cadmium telluride cells were then analyzed to investigate if any changes in microstructure had occurred to explain the observed degradation in efficiency. Figure 5 shows a bright field STEM image of a cross section of a cadmium telluride cell which has been activated using cadmium chloride and then undergone a post-anneal at $400^{\circ} \mathrm{C}$ for 35 seconds without cadmium chloride. This treatment caused a moderate reduction in efficiency from $12 \%$ to $10.88 \%$ as shown in figure 4 . The remarkable image shown in figure 5 clearly shows the presence of stacking faults in a grain located near to the surface. The reemergence of stacking faults in the cadmium telluride layer correlates directly with the reduction in efficiency.

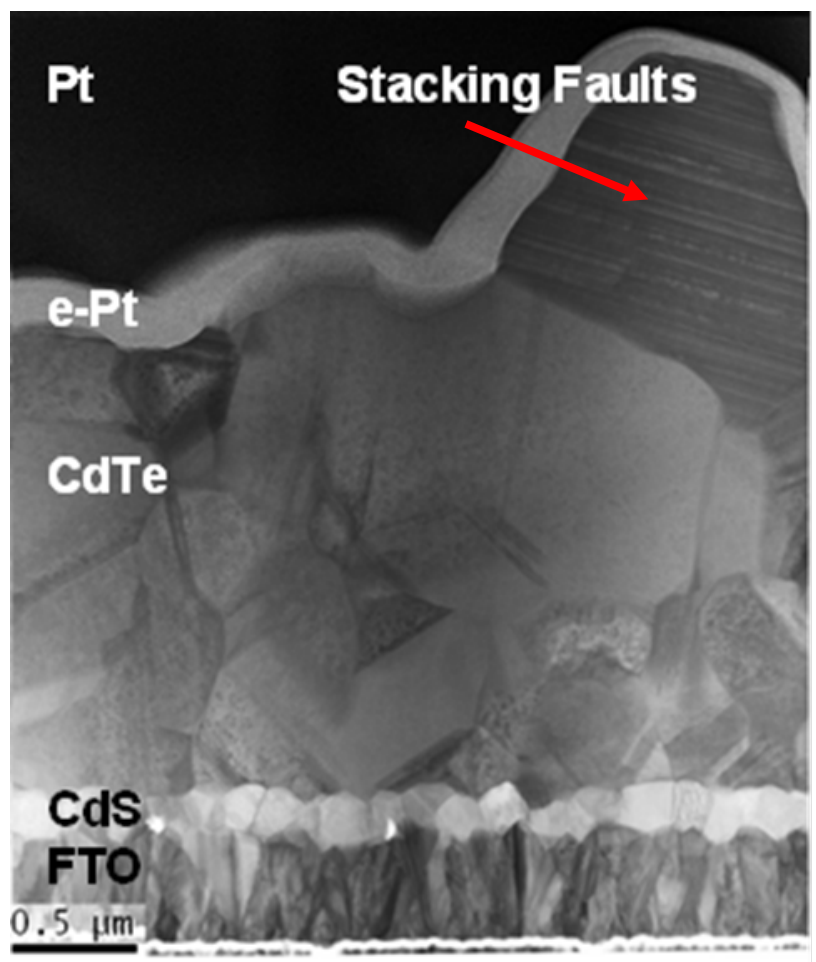

Fig. 5. BF-STEM micrograph of a treated CdTe cell which was then post-annealed at $400^{\circ} \mathrm{C}$ for $35 \mathrm{sec}$. Stacking faults reappear in a grain close to the cell surface.

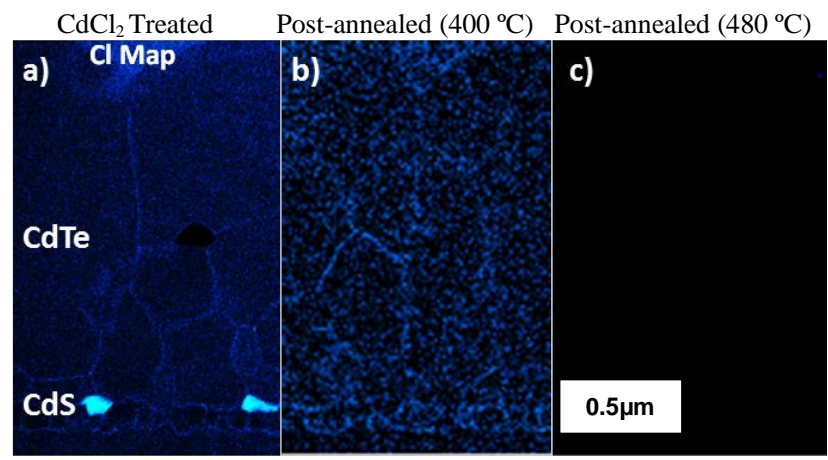

Fig. 6. Chlorine EDX maps from device cross-sections a) $\mathrm{CdCl}_{2}$ passivation treatment b) Post-annealed at $400^{\circ} \mathrm{C}$, c) Postannealed at $480^{\circ} \mathrm{C}$. The reduction in chlorine in the device increases with increasing temperature.

Figure 6 shows the EDX chlorine maps collected from a passivated cell, then post annealed at $400^{\circ} \mathrm{C}$ and then $480^{\circ} \mathrm{C}$. The device annealed at $400^{\circ} \mathrm{C}$ shows that chlorine is still present in the device and is located in the grain boundaries and at the cadmium sulphide interface. However the chlorine map is much less intense than that from the un-annealed cell. The loss of intensity corresponds to a loss of chlorine from the device. This trend is accentuated as the post-annealing temperature is increased to $480^{\circ} \mathrm{C}$ as shown in figure $6 \mathrm{~b}$. This image shows no evidence for the presence of chlorine in the cell within the sensitivity limits of EDX. 


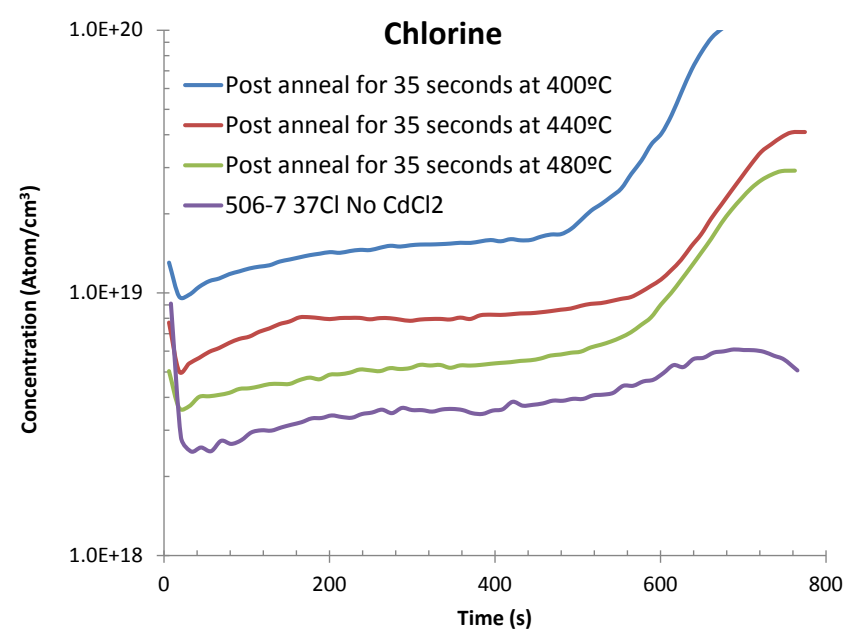

Fig. 7. SIMS depth profiles of chlorine 35 showing the variation in concentration at different post-annealing temperatures. The concentration of chlorine reduces sharply with increasing temperature.

Elemental mapping with EDX has a sensitivity typically in the range $\sim 0.1$ at $\%$ to 1 at $\%$, so dynamic SIMS was used to confirm the removal of chlorine in the postannealed devices. Figure 7 shows the chlorine concentration with depth through a number of devices including the as-deposited cell as a reference. This depth profile shows that there is a residual chlorine concentration in the as-deposited and untreated material. As expected, the chlorine concentration in the cells confirms its sharp reduction with increasing post annealing temperature.

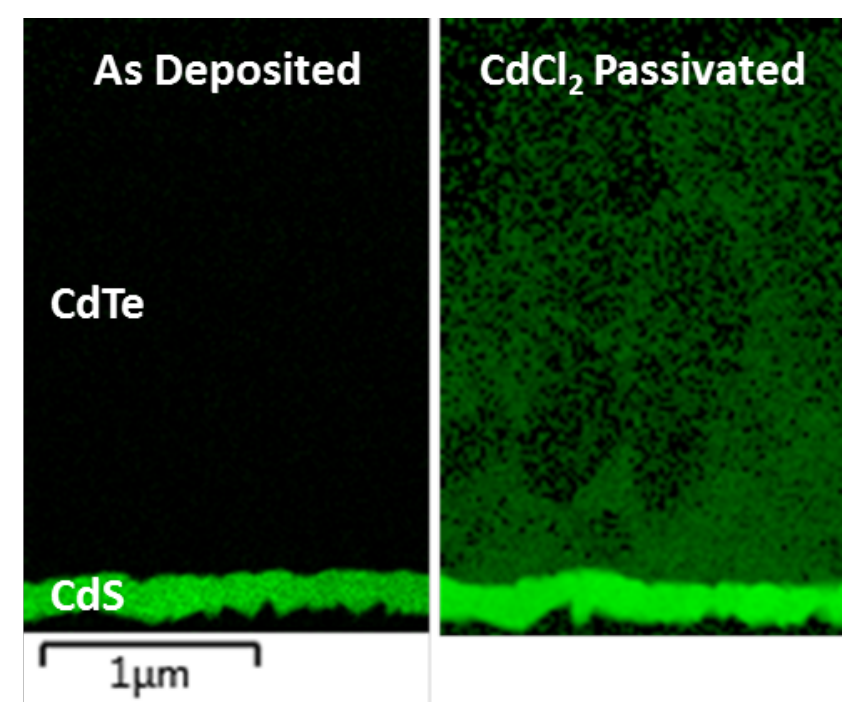

Fig. 8. STEM/EDX sulphur elemental maps for a) As deposited b) cadmium chloride treated devices showing the diffusion of sulphur from the cadmium sulphide into the cadmium telluride

The post annealing process is clearly driving the chlorine out of the device. The removal of chlorine from the grain boundaries appears to cause the re-emergence of high densities of stacking faults in the cadmium telluride grains which in turn correlates with the reduction in efficiency. The chlorine concentration from the three post annealed cells is lowest in the cell annealed at $480^{\circ} \mathrm{C}$.
Figure 8a maps the sulphur elemental from an asdeposited device and figure $10 \mathrm{~b}$ is the sulphur elemental map following the cadmium chloride treatment. Comparison of these images shows that sulphur migration clearly occurs from the cadmium sulphide layer into the cadmium telluride film. The diffusion occurs within the grains and is not concentrated along grain boundaries.

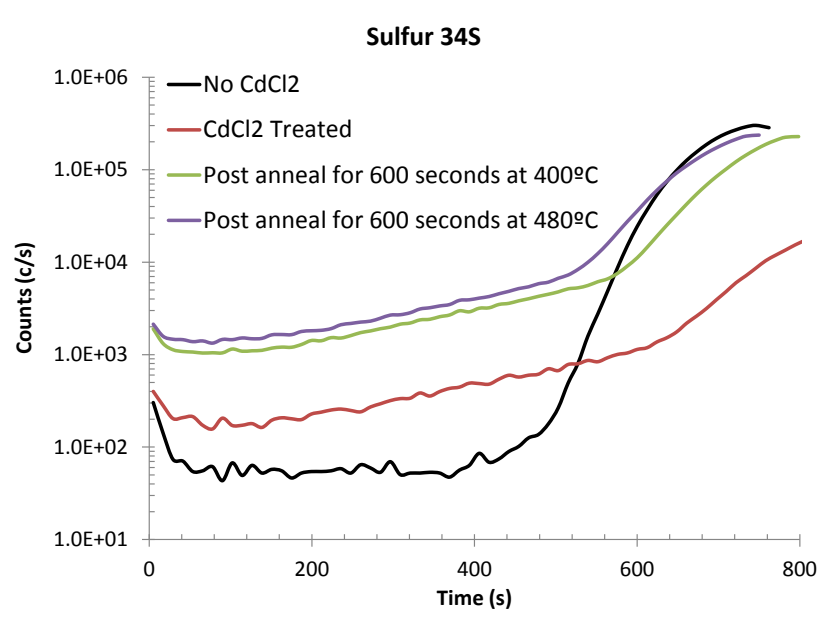

Fig 9. $\quad$ SIMS depth profiles of sulphur 34 showing the variation in concentration at different annealing temperatures

Dynamic SIMS depth profiling analyses were carried out to observe the changes in sulphur concentration in the cadmium telluride following post-annealing at $400^{\circ} \mathrm{C}$ and $480^{\circ} \mathrm{C}$. These sulphur depth profiles are shown in figure 9 and can be compared with the as-deposited device and the high efficiency cell following cadmium chloride passivation but without post-annealing as references.

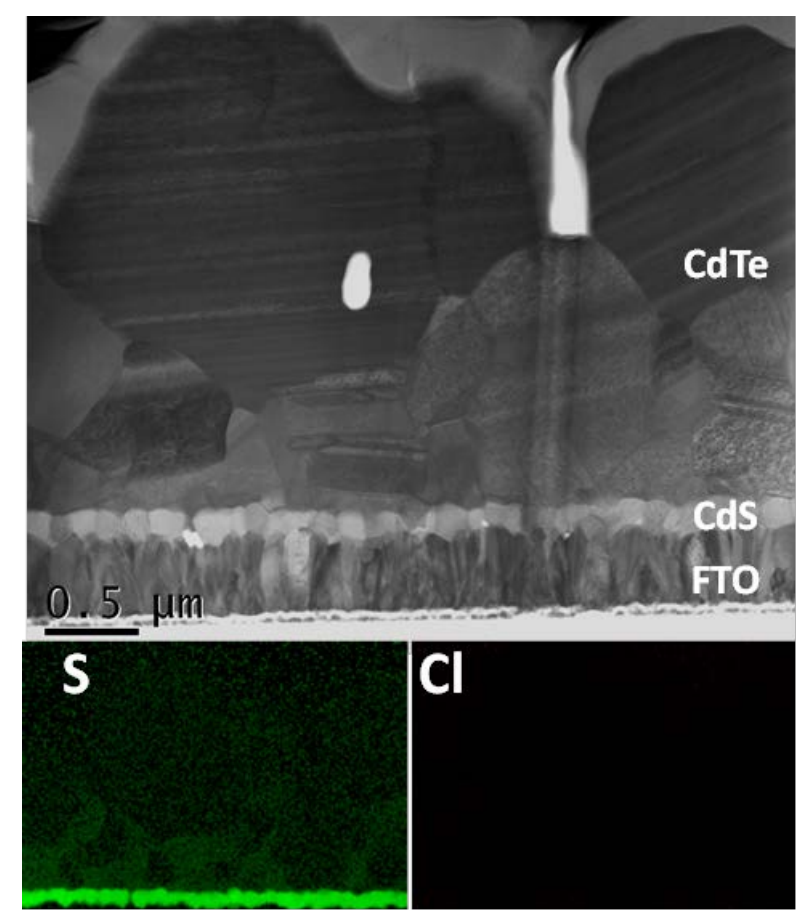

Fig. 10. STEM/EDX of the treated cell post-annealed at $400^{\circ} \mathrm{C}$ for 120 seconds. High densities of stacking faults have reemerged in a number of near surface grains. 
Figure 9 shows an increase in sulphur concentration in the cadmium telluride layer after the cadmium telluride treatment as well as a general broadening of the cadmium sulphide. However, the $\mathrm{J}-\mathrm{V}$ data in figure 4 indicates severe efficiency degradation. Clearly, the loss of efficiency is linked closely with the removal of chlorine rather than sulphur diffusion from the cadmium sulphide layer.

The observation that chlorine is removed by the postannealing process is supported by the EDX/STEM maps shown in figure 10 which show the distribution of sulphur and chlorine in the cadmium telluride following a post annealing treatment at $400^{\circ} \mathrm{C}$ for 120 seconds. The sulphur distribution is unaffected but chlorine is no longer detected even at the grain boundaries. Figure 10 also shows a BF-STEM image revealing the reappearance of stacking faults. There is a clear correlation between the removal of chlorine, the reappearance of high densities of stacking faults and the reduction in cell efficiency.

\section{The Effect of the Post-Annealing Time on Activated Cells}

The efficiency of devices post-annealed for longer periods of time was also investigated. Figure 11 shows the $\mathrm{J}-\mathrm{V}$ curves of a series of cadmium telluride cells.

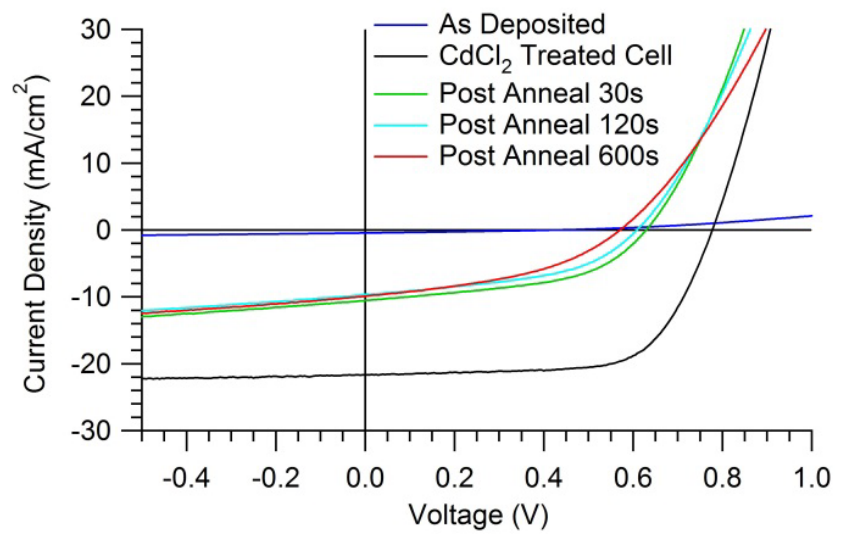

Fig. 11. J-V curves of a treated and untreated cadmium telluride cells and then post-annealed at $480^{\circ} \mathrm{C}$ for 30,120 and 600 seconds

The low efficiency as-deposited cell is without activation using cadmium chloride. The high efficiency device is the cadmium chloride treated device without further post-annealing. The remaining three $\mathrm{J}-\mathrm{V}$ curves correspond to activated devices that have been post annealed at $480^{\circ} \mathrm{C}$ at increasing times of 30 seconds, 120 seconds and 600 seconds. The cell efficiency degrades rapidly and continues to degrade with increasing treatment time corresponding to the reduction in chlorine concentration.

\section{The Effect of a Second Cadmium Chloride Treatment on Post-Annealed Cells}

Figure 12 shows the $\mathrm{J}-\mathrm{V}$ data for untreated and treated cadmium telluride cells, compared with a postannealed cell $\left(480^{\circ} \mathrm{C}\right.$ for 600seconds) exhibiting substantial performance loss and that exact same postannealed cell with a $2^{\text {nd }}$ cadmium chloride passivation treatment.

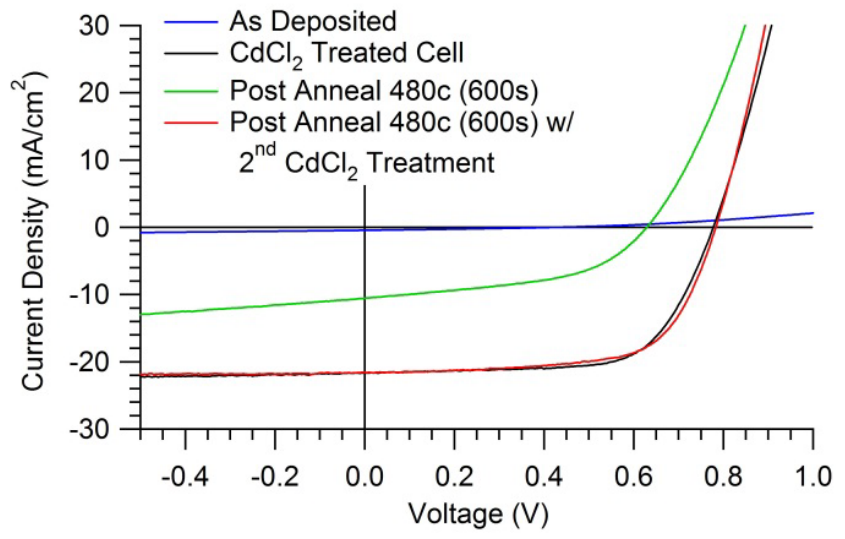

Fig. 12. J-V curves for cadmium telluride cells which have undergone post-annealing treatments and a second treatment with cadmium chloride.

The J-V data shows that post-annealing the cell for 600 seconds at $480^{\circ} \mathrm{C}$ dramatically degrades cell efficiency but still out performs the untreated cadmium telluride material. Then as the post-annealed cell was repassivated with a second standard cadmium chloride treatment, the efficiency of the cell was restored to its original efficiency.

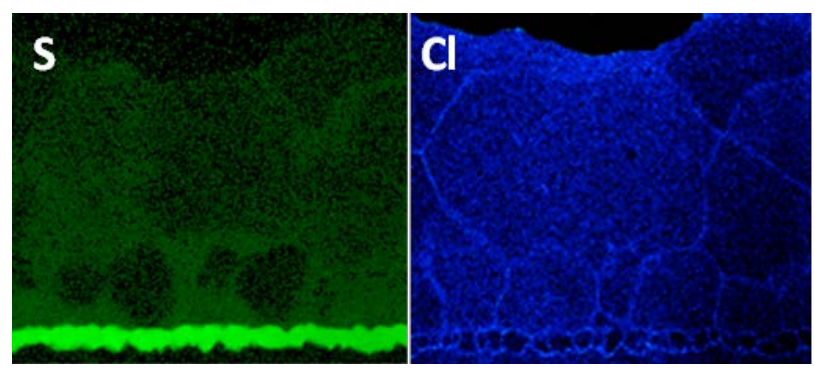

Fig. 13. EDX maps of sulphur and chlorine from a postannealed cell after a second cadmium chloride treatment.

Figure 13 shows EDX maps of sulphur and chlorine from a post-annealed cell (for 600 seconds at $480^{\circ} \mathrm{C}$ ) which then underwent a second cadmium chloride treatment. It shows that chlorine reappears and decorates the grain boundaries of the cadmium telluride and the cadmium sulphide layers. The stacking faults in the cadmium telluride grains are once again removed. The efficiency of this device was restored as shown in the J-V data in figure 12. 
The second cadmium chloride treatment fully restores the functionality of the cells by reintroducing chlorine to the grain boundaries. In-turn this removes the stacking faults which prevent the free movement of holes [4]. This is interesting because it indicates that a process could be devised to control and optimize the location and concentration of chlorine in the devices.

\section{CONCLUSIONS}

The cadmium chloride treatment is a vital process for high efficiency thin film cadmium telluride devices. The effects of this treatment are complex as are the mechanisms at work that allow the devices to operate with high conversion efficiency. We have shown previously that the cadmium chloride process completely removes high densities of stacking faults present in the as deposited material

High densities of stacking faults have been observed in cadmium telluride layers deposited by a number of deposition techniques including close spaced sublimation, electro-deposition and magnetron sputtering. Chlorine diffuses through the cadmium telluride grain boundaries to the cadmium telluride/cadmium sulphide junction and into the cadmium sulphide layer. The presence of chlorine in the grain boundaries appears to be necessary to remove the stacking faults. However, excess chlorine at the junction is harmful to the performance of the devices.

In this study we have shown that a post-annealing treatment can be used to remove chlorine from the device. Surprisingly, the high densities of stacking faults reappear and this corresponds to a decrease in cell efficiency. The re-appearance of the defects corresponds to the removal of chlorine from the grain boundaries. The post-annealing treatment increases the diffusion of sulphur into the cadmium telluride layer.

If these post-annealed cells are then subject to a second cadmium chloride treatment, the stacking faults are again completely removed, and the cell efficiency is restored, chlorine is once more detected at the cadmium telluride and cadmium sulphide grain boundaries and at the cadmium telluride/cadmium sulphide junction. This provides further evidence for the link between the presence of stacking faults, chlorine, and cell efficiency.

In addition to assisting our understanding of the mechanisms at work, these experiments may provide the groundwork for the optimization of a potentially useful post-annealing process which may further improve the grain microstructure but may also help to control and optimize the concentration of chlorine at the cadmium telluride/cadmium sulphide junction.

\section{ACKNOWLEDGEMENTS}

The Loughborough authors are grateful to UKERC for financial assistance through the EPSRC Supergen SuperSolar Hub and the CSU authors to the NSF I/UCRC and AIR programs.

\section{REFERENCES}

[1] M.A. Green; K. Emery; Y. Hishikawa; W. Warta and E.D. Dunlop, "Solar cell efficiency tables (Version 45)," Progress in Photovoltaics, Accelerated Publication, 23, 1-9, 2014.

[2] A, Romeo; D.L. Bätzner; H. Zogg \& A.N. Tiwari, "Recrystallization in CdTe/CdS," Thin Solid Films, 361, 420-425, 2000.

[3] J.M. Kephart; R. Geisthardt, W.S. Sampath, "Sputtered, oxygenated CdS window layers for higher current in CdS/CdTe thin film solar cells." Photovoltaic Specialists Conference,2012.

[4] A. Abbas, G.D. West, J.W. Bowers, P. Isherwood, P.M. Kaminski, B. Maniscalco, P. Rowley, J.M. Walls, K. Barricklow, W.S. Sampath, K.L. Barth, "The Effect of Cadmium Chloride Treatment on Close-Spaced Sublimated Cadmium Telluride Thin-Film Solar Cells, " IEEE Journal of Photovoltaics , vol.3, no.4, pp.1361-1366, 2013.

[5] S. H, Yoo; K.T. Butler; A. Soon; A. Abbas; J.M. Walls; \& A. Walsh, "Identification of critical stacking faults in thinfilm CdTe solar cells,” Applied Physics Letters, 105(6), 2014.

[6] A. Abbas; G.D. West, J.W. Bowers, P.M. Kaminski, B. Maniscalco, J.M. Walls, K.L. Barth, and W.S. Sampath, "Cadmium chloride assisted re-crystallization of CdTe: The effect of annealing over-treatment," In 40th IEEE Photovoltaic Specialist Conference (PVSC), pp. 0701-0706, 2014.

[7] K.L, Barth; R.A. Enzenroth; W.S., Sampath, "Advances in continuous, in-line processing of stable CdS/CdTe devices," Photovoltaic Specialists Conference, 2002. Conference Record of the Twenty-Ninth IEEE, pp. 551- 554, 19-24, 2002.

[8] D. Swanson; R. Lutze; W. Sampath; J. Williams, "Plasma cleaning of TCO surfaces prior to CdS/CdTe deposition," 38th IEEE Photovoltaic Specialists Conference, pp 859-863, 2012. 